\title{
Effects of traditional and cyber homophobic bullying in childhood on depression, anxiety, and physical pain in emerging adulthood and the moderating effects of social support among gay and bisexual men in Taiwan
}

This article was published in the following Dove Press journal:

Neuropsychiatric Disease and Treatment

Chien-Chuan Wang, ${ }^{1,2}$ HuangChi Lin, ${ }^{2,3}$ Mu-Hong Chen, ${ }^{4,5}$ Nai-Ying Ko, ${ }^{6,7}$ Yu-Ping Chang, ${ }^{8}$ I-Mei Lin, ${ }^{9}$ Cheng-Fang Yen ${ }^{2,3}$

'Zuoying Branch of Kaohsiung Armed Forces General Hospital, Kaohsiung, Taiwan; ${ }^{2}$ Department of Psychiatry, Graduate Institute of Medicine and Department of Psychiatry, School of Medicine, College of Medicine, Kaohsiung Medical University, Kaohsiung, Taiwan; ${ }^{3}$ Department of Psychiatry, Kaohsiung Medical University Hospital, Kaohsiung, Taiwan; ${ }^{4}$ Division of Child and Adolescent Psychiatry, Department of Psychiatry, Taipei Veterans General Hospital, Taipei, Taiwan; ${ }^{5}$ Department of Psychiatry, College of Medicine, National Yang-Ming University, Taipei, Taiwan;

${ }^{6}$ Department of Nursing, College of Medicine, National Cheng Kung University, Tainan, Taiwan ${ }^{7}$ Nursing Department and Center for Infection Control, National Cheng Kung University Hospital, Tainan, Taiwan; ${ }^{8} \mathrm{School}$ of Nursing, The State University of New York, University at Buffalo, Buffalo, NY, USA; 'Department of Psychology, College of Humanities and Social Science, Kaohsiung Medical University, Kaohsiung, Taiwan

Correspondence: Cheng-Fang Yen

Department of Psychiatry, Kaohsiung Medical University Hospital, No 100, Tzyou Ist Rd,

Kaohsiung 807, Taiwan

Tel +8867312 II0I ext 6816

Fax +88673134761

Email chfaye@cc.kmu.edu.tw

I-Mei Lin

Department of Psychology, College of Humanities and Social Science, Kaohsiung Medical University,

No 100, Shih-Chuang Ist Rd, Kaohsiung 807,

Taiwan

Tel +88673215422 ext 837

Fax +8867323 3716

Email linII23@gmail.com
Objective: This study examined the differences in the current levels of depression, anxiety, and physical pain in emerging adulthood among gay and bisexual men with various experiences of traditional and cyber homophobic bullying based on gender role nonconformity and sexual orientation and the moderating effects of family and peer support.

Methods: A total of 500 gay or bisexual men (age 20-25 years) in Taiwan were recruited from August 2015 to July 2017. The levels of depression, anxiety, and physical pain among gay or bisexual men who had experienced both traditional and cyber homophobic bullying $(n=109)$, only traditional or cyber bullying $(\mathrm{n}=173)$, and neither traditional nor cyber bullying during childhood ( $\mathrm{n}=218)$ were compared. The moderating effects of family and peer support on the effects of homophobic bullying victimization on depression, anxiety, and physical pain were also examined.

Results: Victims of any type of homophobic bullying in childhood had more severe depression, anxiety, and physical pain in emerging adulthood than nonvictims. Victims of both traditional and cyber homophobic bullying had more severe anxiety in adulthood than victims of only traditional or cyber homophobic bullying. Family but not peer support in childhood moderated the effects of homophobic bullying victimization on current levels of anxiety and physical pain in emerging adulthood among gay and bisexual men.

Conclusion: The results of the present study support that early prevention and intervention for homophobic bullying and enhancement of family support are essential to reduce mental health problems in emergent adults among gay and bisexual men.

Keywords: sexual minority, homophobia, harassment, gender role nonconformity, sexual orientation

\section{Introduction}

Substantial evidence indicates that sexual and gender minorities, including lesbian, gay, bisexual, transgender, and questioning (LGBTQ) youths, experience more severity of depression compared with their heterosexual peers. ${ }^{1,2}$ Disparities in mental health among LGBTQ youths persist into adulthood and adversely affect their development in social relationships, academic achievements, and self-concepts. ${ }^{3}$ A recent systematic review confirmed that bullying victimization is one of the prominent risk factors for depression among LGBTQ youths. ${ }^{4}$ In addition, longitudinal studies have demonstrated 
that prior experiences of homophobic bullying victimization predicted subsequent psychological distress in LGBTQ adolescents. $^{5,6}$ The minority stress hypothesis suggested that homophobic bullying marginalizes LGBTQ youths and negatively affects their mental and physical health. ${ }^{7}$ Given that homophobic bullying is prevalent at schools ${ }^{8}$ and that depression is significantly associated with suicidality, ${ }^{9}$ additional studies examining the factors moderating the association between homophobic bullying victimization and depression in LGBTQ youths are warranted.

Several concerns regarding the effects of homophobic bullying victimization in childhood on mental health disparities in emerging adulthood and the moderators of the effects in LGBTQ youths warrant investigation. First, compared with depression, the relationships between homophobic bullying victimization and anxiety and physical pain in LGBTQ youths have been less examined. A previous study reported that homophobic name-calling by nonfriends was associated with increased anxiety symptoms over a 1-year period among lesbian, gay, and bisexual students, ${ }^{10}$ whereas another study reported that bullying victimization was not associated with anxiety symptoms among young gay and bisexual men. ${ }^{11}$ According to our review of relevant literature, no study has evaluated the relationship between homophobic bullying victimization and physical pain in early adulthood among gay and bisexual men. Because both anxiety and physical pain can affect youths' mental health and quality of life, ${ }^{12,13}$ the effects of homophobic bullying victimization in childhood on anxiety and physical pain in early adulthood among gay and bisexual men warrant further research.

Second, compared with the traditional forms of homophobic bullying, including verbal, social, and physical, ${ }^{14}$ cyber bullying in LGBTQ youths has been less investigated, although almost half the LGBTQ youths experience online peer victimization. ${ }^{15}$ Studies have demonstrated that adolescent victims of cyber bullying are more likely to experience depression $^{16}$ and anxiety ${ }^{16,17}$ than adolescent nonvictims. Another study demonstrated that multiple marginalization indicators interact synergistically and therefore degrade the health status of a population. ${ }^{9}$ Whether combined traditional and cyber bullying has additional effects on mental health problems compared with only traditional or cyber bullying warrants further investigation.

Third, no study has examined the moderating effects of family and peer support on the association between homophobic bullying victimization and depression, anxiety, and physical pain in Asian LGBTQ youths. According to the ecological systems theory, ${ }^{18}$ family and peer support may have protective effects on homophobic bullying. ${ }^{19}$ A review confirmed that family and peer support can protect LGBQT youths from depression. ${ }^{4}$ However, the results of previous studies on the moderating effect of family support on the association between homophobic bullying victimization and mental health problems in LGBTQ youths are inconsistent. Konishi and Saewyc ${ }^{20}$ demonstrated that parental support buffered the negative effect of bullying victimization on social-emotional difficulties, whereas Poteat et $\mathrm{al}^{21}$ did not observe similar buffering effects of family support on the relationship between homophobic victimization and suicidality. Moreover, another study demonstrated that improved friendship quality mediates the association between homophobic harassment and depression. ${ }^{22}$ Compared with European and North American countries, Asian countries exhibit much less tolerance for homosexuality. ${ }^{23}$ LGBTQ youths may hesitate to seek support from families and peers when they experience homophobic bullying. Whether family and peer support can buffer the effects of homophobic bullying victimization on mental health problems in Asian LGBTQ youths warrants further investigation.

Emerging adulthood is a phase of the life span between adolescence and full-fledged adulthood where adolescents become more independent and explore various life possibilities. ${ }^{24}$ Several psychiatric disorders including anxiety, mood, impulse control, and substance use disorders begin during emerging adulthood. ${ }^{25,26}$ The present study examined the differences in the current levels of depression, anxiety, and physical pain in emerging adulthood among gay and bisexual men who had experienced both traditional and cyber homophobic bullying, only traditional or cyber bullying, and neither traditional nor cyber bullying during childhood, as well as the moderating effects of family and peer support on the effects of homophobic bullying victimization on depression, anxiety, and physical pain. According to the minority stress hypothesis, ${ }^{7}$ we hypothesized that gay and bisexual men who had experienced both traditional and cyber homophobic bullying in childhood have the most severe depression, anxiety, and physical pain in emerging adulthood, followed by those who had experienced only traditional or cyber bullying and the nonvictims. According to the ecological systems theory, ${ }^{18}$ we hypothesized that family and peer support buffers the effects of homophobic bullying victimization on depression, anxiety, and physical pain.

\section{Methods}

\section{Participants}

Participants were recruited through advertisements on the Internet, including Facebook, bulletin board systems, and the home pages of five health promotion and counseling 
centers for the LGBT community from August 2015 to July 2017. The advertisement was also mailed to the LGBT student clubs of 25 colleges. Individuals who exhibited any deficits (for example, intellectual disability or substance use) that prevented them from understanding the study purpose or completing the questionnaires were excluded. A total of 500 gay $(n=371)$ or bisexual $(n=129)$ men aged between 20 and 25 years who came from all over Taiwan were recruited in this study. Written informed consent was obtained from all participants prior to assessment. This study was approved by the Institutional Review Board of Kaohsiung Medical University Hospital.

\section{Measures}

\section{Chinese version of the School Bullying Experience Questionnaire}

We used six items from the self-reported Chinese version of the School Bullying Experience Questionnaire (C-SBEQ) to evaluate experiences of traditional bullying in primary (grades 1-6), junior high (grades 7-9), and senior high (grades 10-12) schools ${ }^{27}$ based on their gender role nonconformity and sexual orientation at schools, afterschool classes, tutoring schools, and part-time workplaces. Two forms of traditional bullying victimization were evaluated: verbal ridicule and relational exclusion (three items for experiencing social exclusion, mean name-calling, and ill-speaking; for example, "How often have others spoken ill of you because they thought of you as a sissy [they found you homosexual or bisexual]?"), and physical aggression and theft of belongings (three items for experiencing physical abuse, forced work, and confiscation of money, school supplies, and snacks; for example, "How often have others beaten you up because they thought of you as a sissy [they found you homosexual or bisexual]?"). The responses for these six items were graded on a 4-point Likert scale range as follows: $0=$ never, $1=$ just a little, $2=$ often, and $3=$ all the time. A previous study on C-SBEQ psychometrics revealed that the C-SBEQ has acceptable reliability and validity. ${ }^{27}$ Cronbach's $\alpha$ of the scale for evaluating two forms of bullying based on gender role nonconformity and sexual orientation ranged from 0.70 to 0.86 . In the present study, the participants who rated 2 or 3 for any item were identified as self-reported victims of traditional bullying.

\section{Cyberbullying Experiences Questionnaire}

We used three items from the Cyberbullying Experiences Questionnaire to assess cyber bullying experiences in primary, junior high, and senior high schools ${ }^{28}$ based on their gender role nonconformity and sexual orientation. The three items addressed the experiences of posting mean or hurtful comments; posting upsetting pictures, photos, or videos; and online rumor-spreading through emails, blogs, social media (Facebook, Twitter, Plurk), and pictures or videos; for example, "How often have other students posted mean or hurtful comments on you through emails, blogs, or social media because they thought of you as a sissy (they found you homosexual or bisexual)?" The responses to these items were graded on a 4-point Likert scale, with scores ranging from 0 (never) to 3 (all the time). Cronbach's $\alpha$ values of the scales for evaluating cyber bullying victimization because of gender role nonconformity and sexual orientation were 0.71 and 0.86 , respectively. In the present study, the participants who rated 1 for any item were identified as self-reported victims of cyber bullying.

\section{Mandarin Chinese version of the Center for Epidemiological Studies-Depression Scale (MC-CES-D)}

We used the 20-item self-administered MC-CES-D to assess the frequency of depressive symptoms in the preceding week of the study. ${ }^{29,30}$ The items were graded on a 4-point scale. Higher total MC-CES-D scores indicated more severe depression. Cronbach's alpha for the MC-CES-D in the present study was 0.92 .

\section{State subscale on the State-Trait Anxiety Inventory form $Y$}

We used the 20 items from the self-administered State-Trait Anxiety Inventory (STAI-S) form Y to assess participants' current anxiety symptoms. ${ }^{31,32}$ The items were graded on a 4-point Likert scale, with scores ranging from 1 (not at all) to 4 (very much so). Higher total STAI-S scores indicated more severe anxiety. Cronbach's alpha for the STAI-S in the present study was 0.87 .

\section{Physical pain subscale of the Taiwanese Quality of Life Questionnaire for Adolescents}

We used three items on the pain subscale from the selfadministered Taiwanese Quality of Life Questionnaire for Adolescents to measure physical pain over the preceding 2 weeks, ${ }^{33}$ with questions including "Do you worry about pain?", "Do you have any difficulty in managing or coping with pain?", and "Does your pain interfere with things you need to do?" Each item was rated on a 5-point Likert scale, with scores ranging from 1 (not at all) to 5 (very much). A higher total score indicated more severe physical pain. Cronbach's $\alpha$ coefficient for the pain subscale was 0.72 in the present study. 
Chinese version of the Family and Peer Adaptation, Partnership, Growth, Affection, Resolve (APGAR) Index

We used the 5-item self-administered Chinese version of the Family APGAR Index to measure participants' satisfaction with aspects of family support during childhood. ${ }^{34,35}$ Each item was rated on a 4-point Likert scale, with scores ranging from 0 (never) to 3 (always). We also transformed the Family APGAR Index to the Peer APGAR Index to measure participants' satisfaction with aspects of peer support during childhood. Higher total scores on the Family and Peer APGAR represented a higher level of family and peer support, respectively. Cronbach's $\alpha$ for the Family and Peer APGAR indices in the present study was 0.86 and 0.87 , respectively. In the present study, we classified participants whose total scores on the Family and Peer APGAR indices were higher than the median scores of all participants as having high family and peer support, respectively.

\section{Sociodemographic data}

We assessed participants' age and paternal and maternal education level. In Taiwan, the duration of compulsory fundamental education is 9 years; accordingly, participants were divided into those with a high parental education level (parents completed 9 years of compulsory fundamental education) and those with a low parental education level (parents did not complete 9 years of compulsory fundamental education).

\section{Procedure and statistical analysis}

Research assistants explained the procedures and methods for completing the research questionnaires to the participants individually. The participants could propose any question when they had problems on completing the questionnaires, and the research assistants resolved their problems. Data analysis was performed using SPSS 20.0 statistical software (IBM Corporation, Armonk, NY, USA).

Differences in the current levels of depression, anxiety, and physical pain in emerging adulthood among victims of both traditional and cyber bullying, only traditional or cyber bullying, and nonvictims were examined using analysis of variance (ANOVA). The associations between bullying victimization during childhood, age, parental education level, sexual orientation, and perceived family and peer support during childhood and current levels of depression, anxiety, and physical pain in emerging adulthood were examined using multiple regression analysis.

We also used the standard criteria ${ }^{36}$ to examine whether the effects of bullying victimization during childhood on depression, anxiety, and physical pain in emerging adulthood were different in terms of the participants' age, parental education level, sexual orientation, and perceived family and peer support during childhood. According to the criteria, moderation occurred when the interaction term for the predictor (bullying victimization) and the hypothesized moderator (age, parental education level, sexual orientation, and perceived family and peer support) were significantly associated with the dependent variable (depression, anxiety, and physical pain) after controlling for the main effects of both the predictors and hypothesized moderator variables. If bullying victimization and hypothesized moderators were significantly associated with mental health problems, the interactions (bullying victimization $x$ hypothesized moderators) were further incorporated into the regression analysis to examine the moderating effects. A $p$-value of 0.05 was used to indicate significance in all statistical tests.

\section{Results}

Participants' sociodemographic characteristics, levels of depression, anxiety, and physical pain in emerging adulthood, and experiences of traditional and cyber bullying victimization in childhood are presented in Table 1. In total, 190 (38\%) and $201(40.2 \%)$ participants were reported victims of traditional and cyber homophobic bullying in childhood, respectively, and 282 (56.4\%) were reported victims of any type of homophobic bullying in childhood.

\section{Depression, anxiety, and physical pain among participants who had experienced various types of bullying homophobic victimization}

The differences in the current levels of depression, anxiety, and physical pain in emerging adulthood among victims with various experiences of homophobic bullying in childhood examined using ANOVA are presented in Table 2. The results indicated that victims of both traditional and cyber homophobic bullying had not only more severe depression, anxiety, and physical pain than nonvictims but also more severe anxiety than victims of only traditional or cyber homophobic bullying.

\section{Association between bullying victimization and depression, anxiety, and physical pain}

The associations between homophobic bullying victimization in childhood and current levels of depression, anxiety, 
Table I Demographic characteristics, mental health, and bullying victimization $(\mathrm{N}=500)$

\begin{tabular}{|c|c|c|c|}
\hline Characteristics & n (\%) & Mean (SD) & Range \\
\hline Age (years) & & $22.9(1.6)$ & $20-25$ \\
\hline \multicolumn{4}{|l|}{ Paternal education level } \\
\hline High (more than 9 years) & $385(77.0)$ & & \\
\hline Low ( 9 years or fewer) & $115(23.0)$ & & \\
\hline \multicolumn{4}{|l|}{ Maternal education level } \\
\hline High (more than 9 years) & $388(77.6)$ & & \\
\hline Low ( 9 years or fewer) & $112(22.4)$ & & \\
\hline Perceived family support on the & & $8.5(3.8)$ & $0-15$ \\
\hline \multicolumn{4}{|l|}{ APGAR } \\
\hline High (higher than 9) & $216(43.2)$ & & \\
\hline Low ( 9 or lower) & $284(56.8)$ & & \\
\hline \multicolumn{4}{|l|}{ Perceived peer support on the } \\
\hline \multicolumn{4}{|l|}{ APGAR } \\
\hline High (higher than II) & $273(54.6)$ & & \\
\hline Low (II or lower) & $227(45.4)$ & & \\
\hline \multicolumn{4}{|l|}{ Sexual orientation } \\
\hline Bisexuality & $129(25.8)$ & & \\
\hline Homosexuality & $371(74.2)$ & & \\
\hline Depression on the MC-CES-D & & $17.5(10.3)$ & $0-53$ \\
\hline Anxiety on the STAI-S & & $20.4(11.6)$ & $0-54$ \\
\hline Physical pain problems on the & & $3.9(2.2)$ & $0-12$ \\
\hline \multicolumn{4}{|l|}{ TQOLA } \\
\hline \multicolumn{4}{|l|}{ Bullying victimization } \\
\hline Victims of traditional bullying & $190(38.0)$ & & \\
\hline Victims of cyber bullying & $201(40.2)$ & & \\
\hline Any type of bullying victimization & $282(56.4)$ & & \\
\hline $\begin{array}{l}\text { Victims of both traditional and } \\
\text { cyber bullying }\end{array}$ & $109(21.8)$ & & \\
\hline $\begin{array}{l}\text { Victims of only traditional or } \\
\text { cyber bullying }\end{array}$ & $173(34.6)$ & & \\
\hline
\end{tabular}

Abbreviations: APGAR, Adaptation, Partnership, Growth, Affection, Resolve Index; MC-CES-D, Mandarin Chinese version of the Center for Epidemiological Studies-Depression Scale; STAI-S, State subscale on the State-Trait Anxiety Inventory form Y; TQOLA, Taiwanese Quality of Life Questionnaire for Adolescents.

and physical pain examined using multiple regression analysis are presented in Table 3. The results indicated that after controlling for the effects of other factors, victims of any type of homophobic bullying in childhood had more severe depression $(p<0.001)$, anxiety $(p=0.021)$, and pain $(p<0.001)$ than nonvictims.

\section{Moderators of the association between bullying victimization and mental health problems}

Except among participants who had experienced homophobic bullying victimization, the participants with low family support in childhood had more severe depression $(p<0.001)$, anxiety $(p<0.001)$, and physical pain $(p=0.019)$ than those with high family support. In addition, the participants with low peer support in childhood had more severe depression ( $p=0.007)$ and anxiety $(p=0.007)$ than those with high peer support. Thus, the moderating effects of perceived family and peer support in childhood on the associations between homophobic bullying victimization during childhood and current depression, anxiety, and physical pain levels in emerging adulthood were further examined. The results revealed that the interaction variable of low family support $\times$ victims of homophobic bullying was significantly associated with anxiety $(p=0.012)$ and pain $(p=0.017)$, indicating that family support moderated the associations between homophobic bullying victimization and current anxiety and physical pain levels. Further examination revealed that the positive association between homophobic bullying victimization and anxiety existed only among the participants with low family support $(p<0.001)$, but not among those with high family support $(p=0.585)$. In addition, the positive association between homophobic bullying victimization and physical pain existed only among the participants with low family support $(p<0.001)$, but not among those with high family support ( $p=0.418)$. However, family support did not moderate the association between homophobic bullying victimization and depression, and

Table 2 Differences in depression, anxiety, and pain in emerging adulthood among participants who experienced various types of bullying victimization in childhood ${ }^{\mathrm{a}}$

\begin{tabular}{|c|c|c|c|}
\hline Types of bullying victimization & $\begin{array}{l}\text { Depression on } \\
\text { the MC-CES-D, } \\
\text { mean (SD) }\end{array}$ & $\begin{array}{l}\text { Anxiety on } \\
\text { the STAI-S, } \\
\text { mean (SD) }\end{array}$ & $\begin{array}{l}\text { Physical pain } \\
\text { on the TQOLA, } \\
\text { mean (SD) }\end{array}$ \\
\hline $\begin{array}{l}\text { Victims of both traditional and } \\
\text { cyber bullying (BV) }(n=109,21.8 \%)\end{array}$ & $21.1(10.5)$ & $24.2(12.4)$ & $4.4(2.2)$ \\
\hline $\begin{array}{l}\text { Victims of only traditional or cyber } \\
\text { bullying }(\mathrm{OV})(\mathrm{n}=173,34.6 \%)\end{array}$ & $19.2(10.9)$ & $20.7(11.8)$ & $4.2(2.3)$ \\
\hline Nonvictims (NV) (n=2|8, 43.6\%) & I4.3 (8.7) & $18.2(10.5)$ & $3.3(2.1)$ \\
\hline$F$ & 21.026 & 10.132 & 11.532 \\
\hline$p$-value & $<0.001$ & $<0.001$ & $<0.001$ \\
\hline Post hoc & $\mathrm{BV}, \mathrm{OV}>\mathrm{NV}$ & $\mathrm{BV}>\mathrm{OV}>\mathrm{NV}$ & $\mathrm{BV}, \mathrm{OV}>\mathrm{NV}$ \\
\hline
\end{tabular}

Note: ${ }^{a}$ Analysis of variance.

Abbreviations: MC-CES-D, Mandarin Chinese version of the Center for Epidemiological Studies-Depression Scale; STAI-S, State subscale on the State-Trait Anxiety Inventory form Y; TQOLA, Taiwanese Quality of Life Questionnaire for Adolescents. 


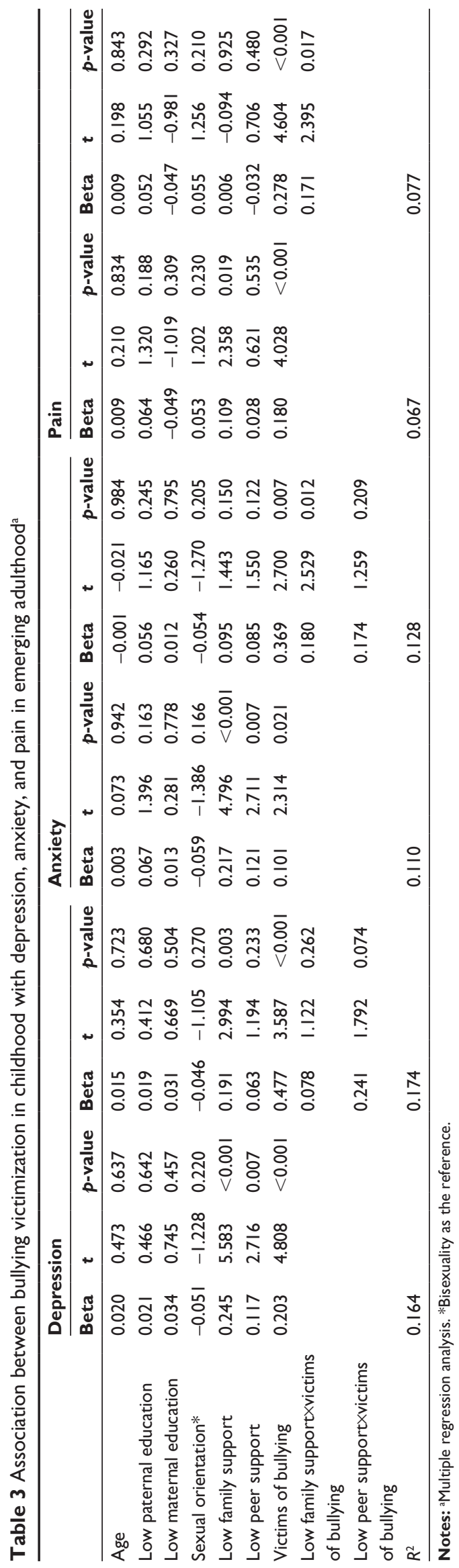

peer support did not moderate the associations between homophobic bullying victimization and depression, anxiety, and physical pain.

\section{Discussion}

The present study demonstrated that victims of any type of homophobic bullying in childhood had more severe depression, anxiety, and physical pain in emerging adulthood than nonvictims. Victims of both traditional and cyber homophobic bullying had more severe anxiety in adulthood than victims of only traditional or cyber homophobic bullying. Family but not peer support in childhood moderated the effects of homophobic bullying victimization on current levels of anxiety and physical pain in adulthood among gay and bisexual men. The positive associations between homophobic bullying victimization and anxiety and physical pain were observed only among the gay and bisexual men with low family support, but not among those with high family support.

Consistent with the results of previous studies, ${ }^{4,10}$ victims of homophobic bullying in childhood had more severe depression and anxiety in emerging adulthood than nonvictims. According to the minority stress hypothesis, ${ }^{7}$ homophobic bullying is one of the most powerful stressors that marginalize LGBTQ youths during the development process. Homophobic bullying causes stressful experiences, anticipation of these stressful experiences, and internalization of negative biases in LGBTQ youths, all of which associate the sexual minority status with mental health problems in adulthood. ${ }^{7,22,37,38}$ In addition, according to the psychological process model, homophobic bullying may disturb the victims' cognitive and emotional controls, which increases the risks of mental health problems. ${ }^{39}$ However, the depression and anxiety proneness may also increase the risks of both being bullied in childhood and high levels of depression and anxiety in emerging adulthood. However, the present study focused on bullying due to gender role nonconformity and sexual orientation, and therefore reduced the possibility of homophobic bullying resulting from depression and anxiety proneness.

The present study demonstrated that victims of homophobic bullying in childhood had more severe physical pain in adulthood than nonvictims. However, the development mechanism of the relationship between homophobic bullying victimization and physical pain remains unknown. A possible mechanism involves the factors that mediate the relationship between bullying victimization and physical pain in gay and bisexual men. Research revealed that both depression 
and anxiety significantly mediated the relationship between bullying victimization and physical pain among adolescents. ${ }^{40}$ Moreover, on the basis of the transactional model of coping, ${ }^{41}$ victims of homophobic bullying may develop physical symptoms such as physical pain to cope with bullying if they evaluate their coping abilities and resources as insufficient. The results of the present study suggested that for physical pain management in gay and bisexual men, clinical and educational professionals should consider the possibility of being bullied and provide adequate interventions to reduce homophobic bullying victimization.

In the present study, no difference in the levels of depression and physical pain was observed between victims of both traditional and cyber homophobic bullying and victims of only traditional or cyber homophobic bullying, whereas victims of both traditional and cyber homophobic bullying had more severe anxiety than victims of only traditional or cyber homophobic bullying. Although additional studies are required to replicate the results and further examine the development mechanism of the discrepancy, the present study results may indicate that multiple forms of bullying may interact synergistically and therefore increase anxiety among gay and bisexual men. Experiencing both traditional and cyber homophobic bullying indicates comprehensive and persistent social difficulties in victims' lives. The victims may have persistent psychological and physiological responses to traditional and cyber bullying, which may result in anxiety. ${ }^{42}$

In the present study, family support in childhood exhibited a buffering effect on the positive associations between homophobic bullying victimization and anxiety and physical pain in gay and bisexual men. Studies have demonstrated that the presence of at least one significant adult is a means for fostering resiliency among youths identified as being "at risk". ${ }^{43,44}$ A review study on the LGBTQ population demonstrated that family support is one of the protective factors for mental health problems. ${ }^{4}$ Although family is not the only source of social support for sexual minority youths, family is the rearing environment that directly supports the youths' during their growth. However, many homosexual and bisexual youths face or fear parental rejection because of their sexual orientation. ${ }^{45}$ Therefore, interventions that help families become more accepting of homosexual and bisexual youths may have beneficial health effects, including decreased anxiety and physical pain.

Given that peer support is one of the prominent protective factors for depression in LGBTQ youths, ${ }^{4}$ we hypothesized that peer support buffers the associations between homophobic bullying victimization and depression, anxiety, and physical pain in sexual minority youths. However, the results of the present study did not support this hypothesis. In addition, a previous study revealed that peer support is less protective than family support for difficulties in school performance among sexual minority youths. ${ }^{46}$ Although the present study did not ask the participants who the bullying perpetrators were (the perpetrators could be victims' peers, school personnel, colleagues at work, or anyone unknown), peers might be the main perpetrators of homophobic bullying. No formal prevention and intervention program that recruited peers as the supporting providers, such as the Gay-Straight Alliance program, ${ }^{47}$ has been implemented in Taiwan. Research on the effects of peer group negativity demonstrated that even if antisocial youths constitute a minority of a peer group, they can shift the behavior climate to a negative direction. ${ }^{48}$ Aggressive peer group social climate accounts for an increase in the use of homophobic language ${ }^{49}$ which is associated with bullying. ${ }^{50}$ Thus, sexual minority youths may not perceive enough peer support for comforting their hurt feelings when they encounter homophobic bullying from peers. Although we did not determine the buffering effect of peer support on the association between homophobic bullying victimization and mental health problems in the present study, we observed that perceived low peer support in childhood was significantly associated with depression and anxiety in emerging adulthood among gay and bisexual men. The results supported that peer support enhancement for sexual minority youths should be included in prevention and intervention programs of bullying for sexual minority youths.

Both gays and lesbians were more likely to be the victims of bullying compared with heterosexuals. ${ }^{51}$ However, research found that boys with sexual minority or gender nonconformity have a higher risk to encounter negative criticism and a lower level of subjective school safety than girls with sexual minority or gender nonconformity. ${ }^{52}$ Moreover, girls have higher levels of depression, ${ }^{53}$ anxiety, ${ }^{54}$ and pain ${ }^{12}$ compared with boys. Thus the present study focused on gay and bisexual men. Further study is needed to examine the relationship of childhood homophobic bullying victimization with depression, anxiety, and pain in emerging adulthood among lesbian and bisexual women.

The present study has several limitations. First, this study obtained data on participants' homophobic bullying victimization and family and peer support retrospectively, and therefore recall bias might have been introduced. However, bullying victims may have strong emotional reactions to such events and may develop vivid and lasting memories of such experiences, thereby reducing the possibility of recall bias. ${ }^{55}$ 
Second, study data were exclusively self-reported. Therefore, the use of only a single data source may have influenced our findings and resulted in shared-method variances. Third, we did not evaluate participants' levels of depression, anxiety, and physical pain in childhood. Whether these mental health problems persisted from childhood to emerging adulthood and interfered with their relationships with bullying victimization warrants further investigation. We also did not evaluate whether the participants have encountered physically aggressive bullying that resulted in persistent physical pain into adulthood. Fourth, we did not examine the homophobic bullying perpetrators of the victims. A previous study demonstrated that homophobic name-calling victimization by friends was not associated with changes in psychological distress among adolescents of any sexual orientation, whereas homophobic name-calling by nonfriends was associated with an increased psychological distress over a 1-year period among homosexual and bisexual adolescents. ${ }^{10}$

\section{Conclusion}

Because of the negative effects of homophobic bullying victimization in childhood on depression, anxiety, and physical pain in emerging adulthood, early prevention and intervention for homophobic bullying is required to reduce mental health problems in emerging adulthood among gay and bisexual men. Anxiety is a mental health problem that warrants routine evaluation, particularly among victims of both traditional and cyber homophobic bullying. Enhancement of family support for sexual minority youths should be included in prevention and intervention programs of bullying for sexual minority youths.

\section{Acknowledgment}

This study was supported by the Ministry of Science and Technology, Taiwan, ROC (grant no MOST 104-2314B-037-024-MY3) and the Kaohsiung Medical University Hospital (grant nos KMUH104-4R60, KMUH105-5R59, and KMUH106-6R67).

\section{Disclosure}

The authors report no conflicts of interest in this work.

\section{References}

1. Marshal MP, Dietz LJ, Friedman MS, et al. Suicidality and depression disparities between sexual minority and heterosexual youth: a metaanalytic review. J Adolesc Health. 2011;49:115-123.

2. Seil KS, Desai MM, Smith M. Sexual orientation, adult connectedness, substance use, and mental health outcomes among adolescents: findings from the 2009 New York City Youth Risk Behavior Survey. Am J Public Health. 2014;104:1950-1956.
3. Mayer KH, Garofalo R, Makadon H. Promoting the successful development of sexual and gender minority youths. Am J Public Health. 2014;104:976-981.

4. Hall WJ. Psychosocial risk and protective factors for depression among lesbian, gay, bisexual, and queer youth: a systematic review. J Homosex. 2018;65:263-316.

5. Birkett M, Newcomb ME, Mustanski B. Does it get better? A longitudinal analysis of psychological distress and victimization in lesbian, gay, bisexual, transgender, and questioning youth. J Adolesc Health. 2015; 56:280-285.

6. Burton CM, Marshal MP, Chisolm DJ, Sucato GS, Friedman MS. Sexual minority-related victimization as a mediator of mental health disparities in sexual minority youth: a longitudinal analysis. $J$ Youth Adolesc. 2013;42:394-402.

7. Meyer IH. Prejudice, social stress, and mental health in lesbian, gay, and bisexual populations: conceptual issues and research evidence. Psychol Bull. 2003;129:674-697.

8. Kosciw JG, Greytak EA, Giga NM, Villenas C, Danischewski DJ. The 2015 National School Climate Survey: The Experiences of Lesbian, Gay, Bisexual, Transgender, and Queer Youth in Our Nation's Schools. New York, NY: GLSEN; 2016.

9. Ferlatte O, Dulai J, Hottes TS, Trussler T, Marchand R. Suicide related ideation and behavior among Canadian gay and bisexual men: a syndemic analysis. BMC Public Health. 2015;15:597.

10. Tucker JS, Ewing BA, Espelage DL, Green HD Jr, de la Haye K, Pollard MS. Longitudinal associations of homophobic name-calling victimization with psychological distress and alcohol use during adolescence. J Adolesc Health. 2016;59:110-115.

11. Katz-Wise SL, Rosario M, Calzo JP, Scherer EA, Sarda V, Austin SB. Associations of timing of sexual orientation developmental milestones and other sexual minority stressors with internalizing mental health symptoms among sexual minority young adults. Arch Sex Behav. 2017; 46:1441-1452.

12. Lee PH, Yeh YC, Hsiao RC, Yen FC, Hu HF. Pain-related quality of life related to mental health and sociodemographic indicators in adolescents. Arch Clin Psychiatry. 2017;44:67-72.

13. Yen CF, Yang P, Ko CH, Yen JY, Hsu FC, Wu YY. The relationships between quality of life and anxiety symptoms and the moderating effects of socio-demographic characteristics in Taiwanese adolescents. Qual Life Res. 2011;20:1071-1078.

14. Basile KC, Espelage DL, Rivers I, McMahon PM, Simon TR. The theoretical and empirical links between bullying behavior and sexual violence perpetration. Aggress Violent Behav. 2009;14:336-347.

15. Ybarra ML, Mitchell KJ, Palmer NA, Reisner SL. Online social support as a buffer against online and offline peer and sexual victimization among U.S. LGBT and non-LGBT youth. Child Abuse Negl. 2015; 39:123-136.

16. Yang SJ, Stewart R, Kim JM, et al. Differences in predictors of traditional and cyber-bullying: a 2-year longitudinal study in Korean school children. Eur Child Adolesc Psychiatry. 2013;22:309-318.

17. Kowalski RM, Limber SP. Psychological, physical, and academic correlates of cyberbullying and traditional bullying. J Adolesc Health. 2013;53(1 Suppl 1):S13-S20.

18. Bronfenbrenner U. Ecological systems theory. In: Vasta R, editor. Six Theories of Child Development: Revised Formulations and Current Issues. London: Jessica Kingsley Publishers Press; 2002:221-288. Available from: https://www.jkp.com/uk/six-theories-of-child-development.html. Accessed March 13, 2018.

19. Hong JS, Garbarino J. Risk and protective factors for homophobic bullying in schools: an application of the social-ecological framework. Educ Psychol Rev. 2012;24:271-285.

20. Konishi C, Saewyc E. Still a target: sexual diversity and power of caring. Sch Psychol Int. 2013;35:504-515.

21. Poteat VP, Mereish EH, Digiovanni CD, Koenig BW. The effects of general and homophobic victimization on adolescents' psychosocial and educational concerns: the importance of intersecting identities and parent support. J Couns Psychol. 2011;58:597-609. 
22. Martin-Storey A, Crosnoe R. Sexual minority status, peer harassment, and adolescent depression. J Adolesc. 2012;35:1001-1011.

23. World Value Survey Association (WVSA) [webpage on the Internet]. World Value Survey Wave 6: 2010-2014. Vienna: WVSA; 2014 Available from: http://www.worldvaluessurvey.org/WVSOnline.jsp. Accessed July 25, 2014.

24. Arnett JJ. Emerging adulthood: a theory of development from the late teens through the twenties. Am Psychol. 2000;55:469-480.

25. Kessler RC, Amminger GP, Aguilar-Gaxiola S, Alonso J, Lee S, Ustün TB. Age of onset of mental disorders: a review of recent literature. Curr Opin Psychiatry. 2007;20:359-364.

26. Kessler RC, Berglund P, Demler O, Jin R, Merikangas KR, Walters EE. Lifetime prevalence and age-of-onset distributions of DSM-IV disorders in the National Comorbidity Survey Replication. Arch Gen Psychiatry. 2005;62:593-602.

27. Yen CF, Kim YS, Tang TC, Wu YY, Cheng CP. Factor structure, reliability, and validity of the Chinese version of the School Bullying Experience Questionnaire. Kaohsiung J Med Sci. 2012;28:500-505.

28. Yen CF, Chou WJ, Liu TL, Ko CH, Yang P, Hu HF. Cyberbullying among male adolescents with attention-deficit/hyperactivity disorder: prevalence, correlates, and association with poor mental health status. Res Dev Disabil. 2014;35:3543-3553.

29. Chien CP, Cheng TA. Depression in Taiwan: epidemiological survey utilizing CES-D. Seishin Shinkeigaku Zasshi. 1985;87:335-338.

30. Radloff LS. The CES-D scale. A self-report depression scale for research in the general population. Appl Psychol Meas. 1977;1:385-401.

31. Chung SK, Long CF. A study of the revised State-trait Anxiety Inventory. Psychol Test. 1984;31:27-36.

32. Spielberger CD, Gorsuch R, Luschene RE, Vagg PR, Jacobs GA. Manual for the State-Trait Anxiety Inventory (Form Y1-Y2). Palo Alto, CA: Consulting Psychologists Press; 1983.

33. Fuh JL, Wang SJ, Lu SR, Juang KD. Assessing quality of life for adolescents in Taiwan. Psychiatry Clin Neurosci. 2005;59:11-18.

34. Chen YC, Hsu CC, Hsu SH, Lin CC. A preliminary study of Family APGAR index. Acta Pediatr Sin. 1980;21:210-217.

35. Smilkstein G. The family APGAR: a proposal for a family function test and its use by physicians. J Fam Pract. 1978;6:1231-1239.

36. Baron RM, Kenny DA. The moderator-mediator variable distinction in social psychological research: conceptual, strategic, and statistical considerations. J Pers Soc Psychol. 1986;51:1173-1182.

37. Toomey RB, Ryan C, Diaz RM, Card NA, Russell ST. Gendernonconforming lesbian, gay, bisexual, and transgender youth: school victimization and young adult psychosocial adjustment. Dev Psychol. 2010;46:1580-1589.

38. Ueno K. Same-sex experience and mental health during the transition between adolescence and young adulthood. Sociol Q. 2010;51: 484-510.

39. Hatzenbuehler ML. How does sexual minority stigma "get under the skin"? A psychological mediation framework. Psychol Bull. 2009; 135:707-730.
40. Yen CF, Lin IM, Liu TL, Hu HF, Cheng CP. Mediating effects of depression and anxiety on the relationship between bullying involvement and pain problems among adolescents in Taiwan. Compr Psychiatry. 2014;55:1415-1421.

41. Lazarus RS, Folkman S. Stress, Appraisal, and Coping. New York, NY: Springer-Verlag; 1984.

42. Hamilton LD, Newman ML, Delville CL, Delville Y. Physiological stress response of young adults exposed to bullying during adolescence. Physiol Behav. 2008;95:617-624.

43. Luthar SS. Resilience and Vulnerability: Adaptations in the Context of Child Adversities. New York, NY: Cambridge University Press; 2003.

44. Werner EE, Smith RS. Overcoming the Odds: High Risk Children from Birth to Adulthood. New York, NY: Cornell University Press; 1992.

45. Savin-Williams RC, Ream GL. Sex variations in the disclosure to parents of same-sex attractions. J Fam Psychol. 2003;17:429-438.

46. Craig SL, Smith MS. The impact of perceived discrimination and social support on the school performance of multiethnic sexual minority youth. Youth Soc. 2011;46:30-50.

47. Russell ST, Muraco A, Subramaniam A, Laub C. Youth empowerment and high school Gay-Straight Alliances. J Youth Adolesc. 2009; 38(7):891-903.

48. Dishion T, McCord J, Poulin F. When interventions harm: peer groups and problem behavior. Am Psychol. 1999;54:755-764.

49. Poteat VP. Contextual and moderating effects of peer group climate on use of homophobic epithets. School Psych Rev. 2008;37:188-201.

50. Poteat VP, Digiovanni CD. When biased language use is associated with bullying and dominance behavior: the moderating effect of prejudice. $J$ Youth Adolesc. 2010;39:1123-1133.

51. Massachusetts Department of Education (MDE). Massachusetts high school students and sexual orientation results of the 2005 youth risk behavior survey. Malden, MA: MDE; 2007. Available from: http://www.mass.gov/cgly/yrbs05.pdf. Accessed March 13, 2018.

52. Diaz EM, Greytak EM, Kosciw JG. The 2007 National School Climate Survey: The Experiences of Lesbian, Gay, Bisexual and Transgender Youth in Our Nation's Schools. New York, NY: GLSEN; 2008.

53. Lin HC, Tang TC, Yen JY, et al. Depression and its association with self-esteem, family, peer and school factors in a population of 9,586 adolescents in southern Taiwan. Psychiatry Clin Neurosci. 2008;62: 412-420.

54. Yen CF, Ko CH, Wu YY, Yen JY, Hsu FC, Yang P. Normative data on anxiety symptoms on the Multidimensional Anxiety Scale for Children in Taiwanese children and adolescents: differences in sex, age, and residence and comparison with an American sample. Child Psychiatry Hum Dev. 2010;41:614-623.

55. Ladd GW, Kochenderfer-Ladd B. Identifying victims of peer aggression from early to middle childhood: analysis of cross-informant data for concordance, estimation of relational adjustment, prevalence of victimization, and characteristics of identified victims. Psychol Assess. 2002; 14:74-96.
Neuropsychiatric Disease and Treatment

\section{Publish your work in this journal}

Neuropsychiatric Disease and Treatment is an international, peerreviewed journal of clinical therapeutics and pharmacology focusing on concise rapid reporting of clinical or pre-clinical studies on a range of neuropsychiatric and neurological disorders. This journa is indexed on PubMed Central, the 'PsycINFO' database and CAS,

\section{Dovepress}

and is the official journal of The International Neuropsychiatric Association (INA). The manuscript management system is completely online and includes a very quick and fair peer-review system, which is all easy to use. Visit http://www.dovepress.com/testimonials.php to read real quotes from published authors. 